\title{
El ejercicio físico aumenta el daño pulmonar inducido por la exposición aguda e intermitente a 0,5 ppm de ozono en ratas juveniles
}

\author{
MANUEL OYARZÚN G.*, NELSON DUSSAUBAT D.*, MARÍA EUGENIA MILLER A.*, \\ MARTÍN LÓPEZ A.**, GASTÓN MÉNDEZ L.** y JORGE MIRANDA G. **
}

\begin{abstract}
Physical exercise increases pulmonary damage induced by acute and intermittent exposure to $0.5 \mathrm{ppm}$ of ozone in juvenile rats
\end{abstract}

Tropospheric ozone $\left(\mathrm{O}_{3}\right)$ is the major oxidant of photochemical smog. Being an air pollutant, its effects are related to effective dose $=$ [Concentration] $\times$ [exposure time] $\times$ [pulmonary ventilation] . Objective: Determine whether physical exercise -that increases pulmonary ventilation- is able to augment the pulmonary damage induced by $\mathrm{O}_{3}$ exposure in resting rats. Material and Methods: Four series of juvenile Sprague-Dawley rats were used. Two series were exposed to $0.5 \mathrm{ppm} \mathrm{O}_{3}$ (4 hours a day for 2 days) at rest $(n=13)$ or during exercise $(n=12)$. Two control series breathed filtered air (FA) at rest $(n=13)$ or during exercise sessions $(n=13)$, in a vertical rotary wheel (15 min exercise alternated with 15 min resting until to completing 4 hours a day for 2 days). Rats were euthanized and wet weight / dry weight ratio (W/D ratio) was determined in left lung. Total cell counting, total protein content and $\gamma$-glutamyltraspeptidase (GGT) activity were determined in the right lung bronchoalveolar lavage fluid (BALF). Results: W/D weight ratio as well as total cell counting and protein content increased in $B A L F$ from resting rats exposed to $O_{3}$ as compared with resting rats breathing $F A(p<0.05$ ANOVA \& Newman-Keuls test). GGT activity in BALF increased in rats under exercise breathing FA as compared with resting rats breathing $F A(p<0.05)$. GGT, proteins and cells counting increased in BALF from series [exercise $+\mathrm{O}_{3}$ ] as compared to series [resting $\left.+\mathrm{O}_{3}\right](p<0.05)$. Conclusion: Physical exercise increases lung damage induced by intermittent and acute $0.5 \mathrm{ppm} \mathrm{O}_{3}$ exposure in juvenile rats.

Key words: Ozone; exercise; lung damage; $\gamma$-glutamiltranspeptidase; bronchoalveolar lavage.

\section{Resumen}

El ozono $\left(\mathrm{O}_{3}\right)$ troposférico es el principal oxidante del esmog fotoquímico. Como es un contaminante aéreo, sus efectos están relacionados con la dosis efectiva $=$ [Concentración] $\times$ [tiempo de exposición] $\times$ [ventilación minuto]. Objetivo: Determinar si el ejercicio físico-que aumenta la ventilación minuto- puede aumentar el daño pulmonar inducido por la exposición a $\mathrm{O}_{3}$ en ratas en reposo. Material y Métodos: Se usó 4 series de ratas Sprague-Dawley juveniles. Dos series fueron expuestas a 0,5 ppm de $\mathrm{O}_{3}$ (4 h diarias por 2 días) en reposo $(n=13)$ o durante ejercicio $(n=12)$. Dos series control respiraron aire filtrado $(A F)$ en reposo $(n=13)$ o durante sesiones de ejercicio $(n=13)$, en una rueda vertical giratoria (15 min de ejercicio alternados con 15 min de descanso hasta completar 4 h diarias durante 2 días). Las ratas fueron eutanasiadas y se determinó la razón peso húmedo/peso seco (PH/PS) en el pulmón izquierdo. En el lavado broncoalveolar (LBA) del pulmón derecho, se determinó recuento total de células, proteinas totales y actividad de $\gamma$-glutamiltraspeptidasa (GGT). Resultados: la razón PH/PS y el recuento de células y las proteínas del LBA aumentaron en las ratas en reposo expuestas a $\mathrm{O}_{3}$ comparadas con las ratas en reposo que respiraron $A F(p<0,05$ ANOVA \& Newman-Keuls). La actividad de GGT en el LBA fue mayor en las ratas que en ejercicio respiraron

* Laboratorio de Investigaciones Respiratorias, Programa de Fisiopatología, Instituto de Ciencias Biomédicas. Facultad de Medicina, Universidad de Chile.

** Alumnos Escuela de Medicina, Universidad de Chile. 
$A F$ en comparación con las ratas que respiraron AF en reposo $(p<0,05)$. Hubo aumento de $G G T$, proteinas y recuento de células en el $L B A$ de la serie [ejercicio $+O_{3}$ ] comparada con la serie [reposo $\left.+\mathrm{O}_{3}\right]$ ( $\left.p<0,05\right)$. Conclusión: El ejercicio físico aumenta el daño pulmonar inducido por la exposición aguda e intermitente a $0,5 \mathrm{ppm}$ de $\mathrm{O}_{3}$ en ratas juveniles.

Palabras clave: Ozono; ejercicio; daño pulmonar; y-glutamiltranspeptidasa; lavado broncoalveolar.

\section{Introducción}

El ozono $\left(\mathrm{O}_{3}\right)$ es el principal componente del esmog fotoquímico. Es considerado un contaminante secundario y en las zonas urbanas se forma a partir de los compuestos orgánicos volátiles y de los óxidos de nitrógeno, a través de complejas reacciones químicas catalizadas por la radiación solar. Esto explica que en la Región Metropolitana, la concentración de $\mathrm{O}_{3}$ troposférico comienza a elevarse en primavera alcanzando sus máximos valores en verano alrededor de las $14 \mathrm{~h}$ y en las zonas altas de la ciudad que reciben mayor radiación solar (sector nor-oriente) ${ }^{1}$.

La mayor parte del ozono (90\%) está en la estratósfera formando la "capa de ozono" que bloquea la radiación ultravioleta, protegiendo a la biósfera de sus efectos. El 10\% restante se encuentra a nivel de la tropósfera, donde puede ejercer sus efectos deletéreos sobre la población.

El ozono es un poderoso oxidante ${ }^{2}$, por lo que al ser inhalado provoca daños al sistema respiratorio, debido a la formación de radicales libres, peróxido de hidrógeno y aldehídos, compuestos causantes de inflamación, estimulación de las aferencias nerviosas de las vías aéreas y daño del epitelio respiratorio en toda su extensión, principalmente en las células ciliadas y en los neumocitos tipo $\mathrm{I}^{1}$.

Numerosos estudios demuestran que la exposición aguda a ozono provoca en voluntarios sanos una disminución de los valores espirométricos, síntomas de irritación traqueal ${ }^{3}$, hiperreactividad bronquial $^{4}$, disminución del rendimiento atlético ${ }^{5}$ e inflamación ${ }^{6}$, entre otras alteraciones. Por otra parte, entre los efectos de la exposición crónica a ozono se han descrito: índices espirométricos inferiores a la media normal debido a un menor desarrollo de la vía aérea ${ }^{7}$, daño en las células epiteliales, remodelación epitelial e intersticial ${ }^{8}$ y bronquiolización alveolar 9 .

Existe una diversidad de factores que determinan la respuesta del organismo frente a la exposición aguda o crónica al ozono, siendo los principales los siguientes ${ }^{1}$ : a) Dosis efectiva del ozono $=$ [concentración $] \cdot[$ tiempo de exposición $]$ - [ ventilación minuto]; b) Edad del individuo, siendo más sensibles las edades extremas; c) De- sarrollo de tolerancia y/o adaptación; d) Factores genéticos; e) Interacción con otros contaminantes y f) Enfermedades cardiorrespiratorias previas. El daño del organismo por $\mathrm{O}_{3}$ se produce especialmente en el sistema respiratorio, y actividades que ayudarían a mantener un nivel de vida saludable, en condiciones de altas concentraciones de $\mathrm{O}_{3}$, podrían ser perjudiciales para la salud. Es el caso del ejercicio físico ${ }^{10,11}$, el cual es practicado con alta frecuencia en las épocas de mayor contaminación por $\mathrm{O}_{3}$, y paradojalmente, un número importante de deportistas aficionados realizan su actividad en áreas verdes del sector norte, y nororiente de la Región Metropolitana, en horarios con alta contaminación por $\mathrm{O}_{3}$.

Considerando el estudio de Gong y cols. ${ }^{12}$, el cual estableció que bajos niveles de ozono en un ambiente caluroso, interfiere con el ejercicio físico de ciclistas, nos propusimos dilucidar si un ejercicio físico estandarizado es capaz de aumentar el daño pulmonar producido en nuestro modelo experimental por la exposición aguda e intermitente $\mathrm{a}_{3}(0,5 \mathrm{ppm}, 4 \mathrm{~h}$ diarias por 2 días $)$ en ratas en reposo.

\section{Material y Métodos}

Se usaron ratas de la cepa Sprague-Dawley, machos, de dos meses de edad y con un peso corporal promedio de $211 \pm 11 \mathrm{~g}$ (DS), que desde su nacimiento en el bioterio del Programa de Fisiopatología Oriente, Facultad Medicina, Universidad de Chile, habían respirado aire filtrado para $\mathrm{PM}_{10}$. Estas ratas fueron separadas en 4 series:

a) Serie control $(n=13)$ : ratas mantenidas en el ambiente del bioterio.

b) Serie control ejercicio $(n=13)$ : realizaron ejercicio estandarizado respirando aire filtrado.

c) Serie reposo $+0,5 \mathrm{ppm}$ de $\mathrm{O}_{3}(\mathrm{n}=13)$ : expuestas a $\mathrm{O}_{3}$ en sus jaulas con agua y alimento, pero sin realizar ejercicio.

d) Serie ejercicio $+0,5 \mathrm{ppm}$ de $\mathrm{O}_{3}(\mathrm{n}=12)$ : expuestas a $\mathrm{O}_{3}$, mientras realizaban ejercicio.

\section{Procedimientos experimentales}

Inicialmente las ratas fueron expuestas a 1 ppm de ozono durante $4 \mathrm{~h}$, en 2 días consecutivos, pero los resultados obtenidos con tal dosis 
fueron devastadores: fallecimiento de 5 de un total de 8 ratas $(63 \%)$ de la serie $\left[\mathrm{O}_{3}+\right.$ ejercicio] antes de completar el protocolo $\left(\mathrm{p}<0,05 ; \chi^{2}\right)$ y en tres de ellas se detectó bronconeumonía en la histopatología (Figura 1). Ante estos resultados preliminares decidimos disminuir la dosis de ozono a $0,5 \mathrm{ppm}$. La exposición a $\mathrm{O}_{3}$ en reposo se efectuó colocando las jaulas que contenían a los animales con agua de bebida y alimento "ad libitum", en una cámara de $0,96 \mathrm{~m}^{3}$. La exposición a $\mathrm{O}_{3}$ en ejercicio se realizó colocando las ratas dentro de la cámara de exposición en una rueda de ejercicio. El ozono fue producido por un generador (Ozocav, modelo ZT21, Interozone S.A., Chile), alimentado con aire comprimido y vertido a la cámara de vidrio, que cuenta con un agitador de aire, y una salida exterior provista de un filtro de carbono, para la inactivación del $\mathrm{O}_{3}$.

La concentración de $\mathrm{O}_{3}$ en el aire de la cámara de exposición fue medida en forma continua con un analizador de ozono ambiental (Termo Enviroment Instrumental, modelo 49i, Franklin, Mass). También se efectuaron mediciones de temperatura y humedad relativa cada $30 \mathrm{~min}$. La cámara contenía hidróxido de bario, un absorbente de $\mathrm{CO}_{2}$, que al saturarse cambia de color.

\section{Estandarización y acondicionamiento del ejercicio}

Las ratas fueron sometidas a una sesión de adaptación al ejercicio, colocándolas durante 1 hora, dentro de una rueda vertical de ejercicio, construida en el laboratorio, cuyo perímetro es de $55 \mathrm{~cm}$, conectada a un motor eléctrico que hacía girar la rueda a $5 \mathrm{rpm}$. El ejercicio se realizó por períodos de $15 \mathrm{~min}$, con $15 \mathrm{~min}$ de descanso, hasta completar $1 \mathrm{~h}$. Tanto las ratas sometidas a ejercicio respirando aire ambiental, como las expuestas a $\mathrm{O}_{3}$, fueron sometidas a ejercicio por 2 sesiones de $4 \mathrm{~h}$ de duración cada una. En cada sesión realizaron períodos de ejercicio de $15 \mathrm{~min}$, seguido de un período de descanso también de 15 min, hasta completar $4 \mathrm{~h}$ por sesión. En total las ratas corrieron a una velocidad de $2,75 \mathrm{~m} / \mathrm{min}$, recorriendo una distancia total de $330 \mathrm{~m}$ en cada sesión.

\section{Exposición a ozono}

Las ratas fueron expuestas durante $4 \mathrm{~h}$ a 0,5 ppm de $\mathrm{O}_{3}$ en cada sesión y luego devueltas al bioterio. Fueron expuestas en grupos al ozono hasta completar el total de 13 ratas por serie con 2 períodos de exposición. Al término de la última sesión de exposición, por razones operacionales las ratas fueron mantenidas en el bioterio por $20 \mathrm{~h}$ aproximadamente antes de ser sometidas a los procedimientos experimentales finales.

Estos consistieron en anestesiar a la rata con ketamina $100 \mathrm{mg} / \mathrm{kg}$ im y xilacina $10 \mathrm{mg} / \mathrm{kg} \mathrm{im}$ asociada a atropina $0,04 \mathrm{mg} / \mathrm{kg} \mathrm{im}$, y una vez que alcanzaron un nivel profundo de anestesia fueron eutanasiadas por exanguinación, mediante punción de la aorta abdominal. Luego, los pulmones fueron extraídos a través de una toracotomía media esternal y separados para pesarlos y desgasificarlos en una cámara de vacío (-100 $\mathrm{mmHg}$ ). En el pulmón izquierdo se determinó la relación peso húmedo/peso seco. El peso seco se determinó colocando el pulmón izquierdo en una estufa de cultivo a $70^{\circ} \mathrm{C}$ y pesándolo diariamente hasta obtener peso constante. El lavado broncoalveolar (LBA) se efectuó en el pulmón derecho

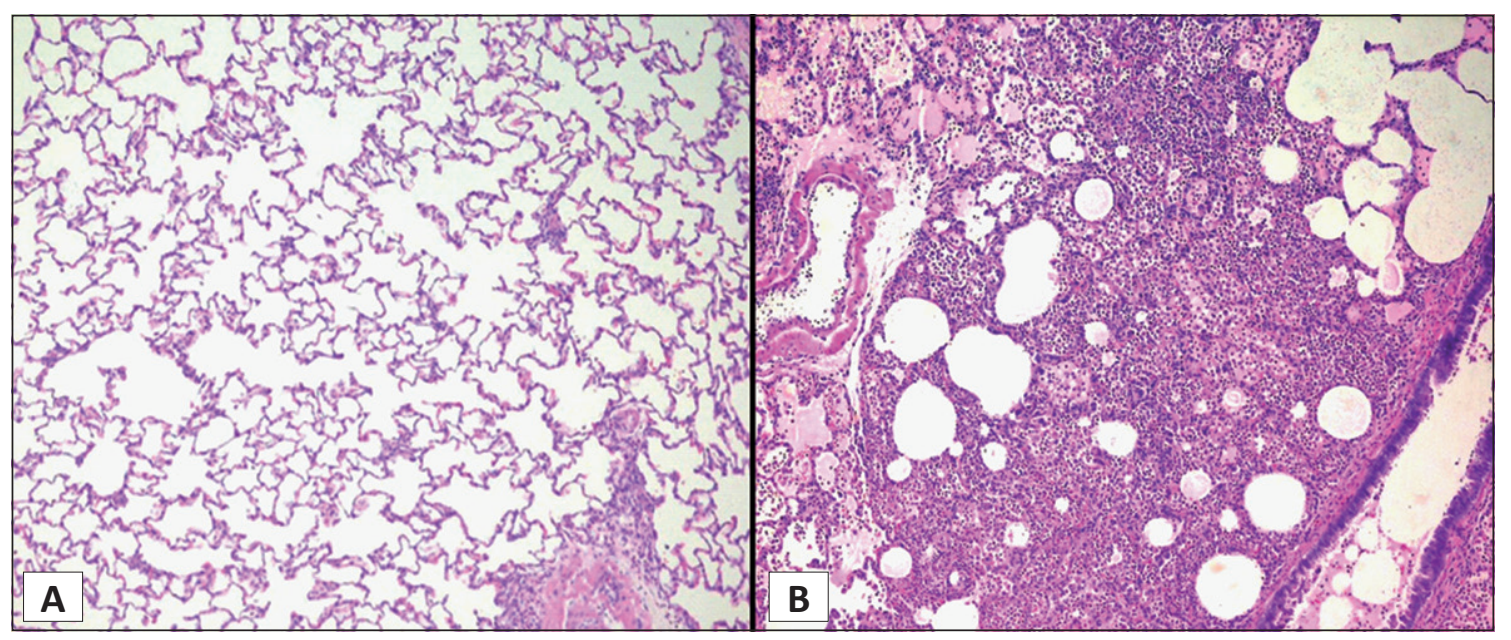

Figura 1. A: Histología de pulmón de rata normal 200x H-E. B: Histopatología de pulmón de rata fallecida en exposición a 1 ppm de ozono durante ejercicio (100x H-E). Bronconeumonía hemorrágica que explica la causa de muerte, alvéolos con exudado seroso y hemorrágico y aumento de los macrófagos alveolares. 
con $\mathrm{NaCl}$ al $0,9 \%$ a capacidad pulmonar total a $4^{\circ} \mathrm{C}$ y se repitió 4 veces, colectándose la mezcla de los 4 lavados en un receptáculo plástico. El LBA se centrifugó a $102 \mathrm{~g}$ por $10 \mathrm{~min}$ a $4^{\circ} \mathrm{C}$, para separar el sobrenadante de las células. En alícuotas del sobrenadante se determinó la cantidad de proteínas totales ${ }^{13}$ y la actividad enzimática de la $\gamma$-glutamiltranspeptidasa: GGT ${ }^{14}$.

En una alícuota del LBA sin centrifugar, se realizó el recuento total de células, usando una cámara de Neubauer y un microscopio óptico Olympus BH-2 (Japón). El protocolo experimental (CBA\# 0426 FMUCH) fue aprobado por la Comisión de Bioética de la Facultad de Medicina, Universidad de Chile.

\section{Análisis estadístico}

En el análisis estadístico de los resultados se utilizó el programa GraphPad Prism 5.0. Para el análisis de las razones peso húmedo/peso seco y peso pulmonar/peso corporal, la actividad de GGT, contenido de proteínas y recuento de células en el LBA se utilizó ANOVA y prueba de Newman-Keuls. Se consideró una diferencia significativa entre los promedios si el valor de $p \leq 0,05$. En experimentos previos realizados en el laboratorio se ha determinado que la DS combinada de la GGT en el LBA de ratas expuestas $\mathrm{a} \mathrm{O}_{3}$ en diversos regímenes, fue de $13 \%$. Suponiendo una diferencia entre medias del $7 \%$ con un poder de $95 \%$ se calculó un total de 13 ratas por cada serie.

\section{Resultados}

La exposición a ozono en dosis de $0,5 \mathrm{ppm}$ produjo una disminución significativa del peso corporal de las ratas ( $\mathrm{p}<0,05$; ANOVA) luego de la primera exposición a ozono tanto en ejercicio como en reposo (Figura 2).

La relación peso pulmonar/peso corporal presentó un aumento significativo en las series expuestas a 0,5 ppm ozono ( $\mathrm{p}<0,0001$; ANOVA) comparada con las series que respiraron aire filtrado. El análisis comparativo de la serie [ejercicio $+0,5 \mathrm{ppm}$ de $\mathrm{O}_{3}$ ] versus la serie [reposo $+0,5$ ppm $\mathrm{O}_{3}$ ] detectó un aumento significativo de la relación peso pulmonar/peso corporal ( $\mathrm{p}<0,05$; Newman-Keuls) (Figura 3). La relación peso húmedo/peso seco del pulmón, índice del contenido acuoso de este órgano, aumentó significativamente en las series expuestas a $0,5 \mathrm{ppm}$ de ozono $(\mathrm{p}<0,05$; ANOVA) (Figura 4), no encontrándose diferencias significativas entre las ratas que realizaron ejercicio y las que se mantuvieron en reposo durante la exposición a ozono.

\section{Análisis del lavado broncoalveolar (LBA)}

Hubo un aumento significativo del recuento de células totales y de proteínas totales entre las ratas expuestas a $0,5 \mathrm{ppm}$ de ozono respecto a las ratas expuestas a aire ambiental $(\mathrm{p}<0,0001$; ANOVA), además de una diferencia significativa en estas mismas mediciones entre las ratas que realizaron ejercicio y las que se mantuvieron en reposo ( $p<0,05$; Newman-Keuls) (Figuras 5 y 6). Respecto a la actividad de la GGT, hubo un aumento significativo en las ratas expuestas a ozono + ejercicio respecto a las que estaban en reposo y expuestas a ozono o respirando aire filtrado y también respecto a las ratas que realizaron ejercicio físico y que respiraron aire filtrado ( $p<0,05$; Newman-Keuls). Es destacable que esta última serie (aire filtrado + ejercicio) presentó un aumento significativo de GGT respecto a las ratas que estaban en reposo y expuestas a ozono ( $\mathrm{p}<0,05$; Newman-Keuls) (Figura 7).

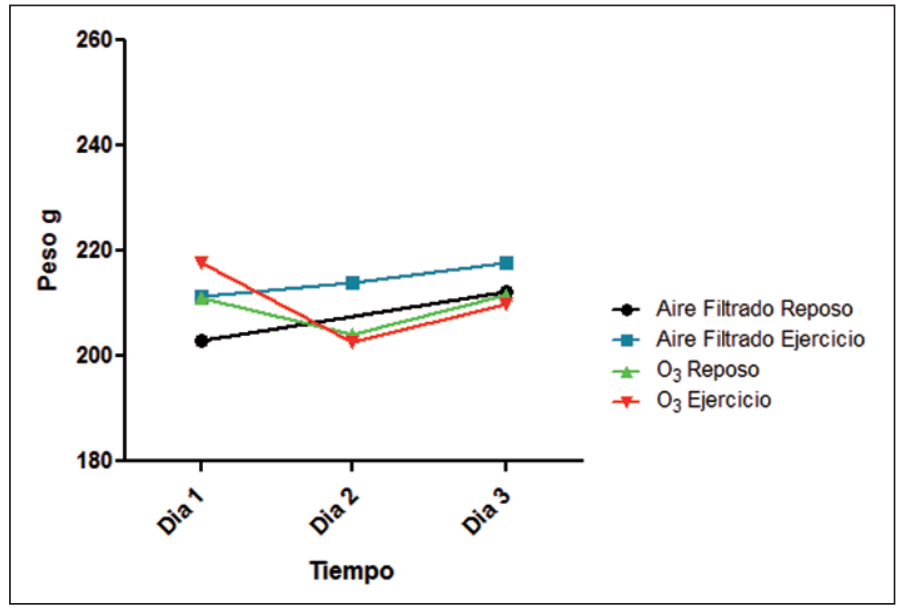

Figura 2. Evolución del peso corporal en ratas expuestas a $0,5 \mathrm{ppm}$ de $\mathrm{O}_{3}$ o aire filtrado en reposo y en ejercicio. Día 1 y 2: exposición a ozono o a aire filtrado en reposo o en ejercicio. Día 3 corresponde a los procedimientos experimentales finales, $20 \mathrm{~h}$ después de cesada la última exposición (ver texto). ${ }^{*} \mathrm{p}<0,05$. 


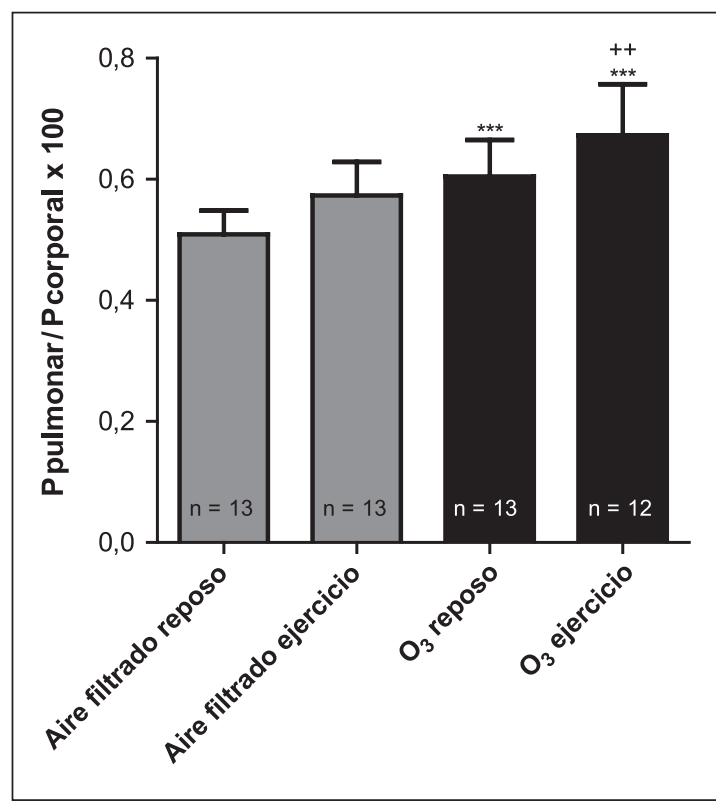

Figura 3. Relación peso pulmonar/peso corporal en ratas expuestas a $0,5 \mathrm{ppm}$ de $\mathrm{O}_{3}$ o a aire filtrado en reposo y en ejercicio. La altura de cada columna representa el valor promedio +1 DS. $++\mathrm{p}<0,05$ al comparar series ozono en reposo versus ozono en ejercicio; $* * * p<0,0001$ al comparar series con ozono versus series con aire filtrado.

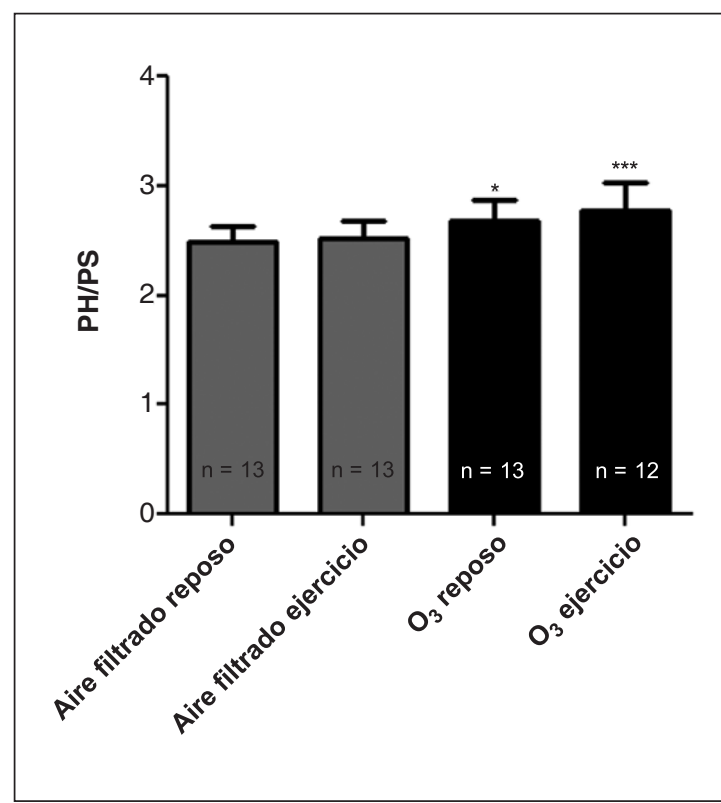

Figura 4. Relación peso húmedo (PH)/peso seco (PS) del pulmón en ratas expuestas a $0,5 \mathrm{ppm}$ de $\mathrm{O}_{3}$ o a aire filtrado en reposo y en ejercicio. ${ }^{*} * * \mathrm{p}=0,002$ al comparar series con ozono versus series con aire filtrado.

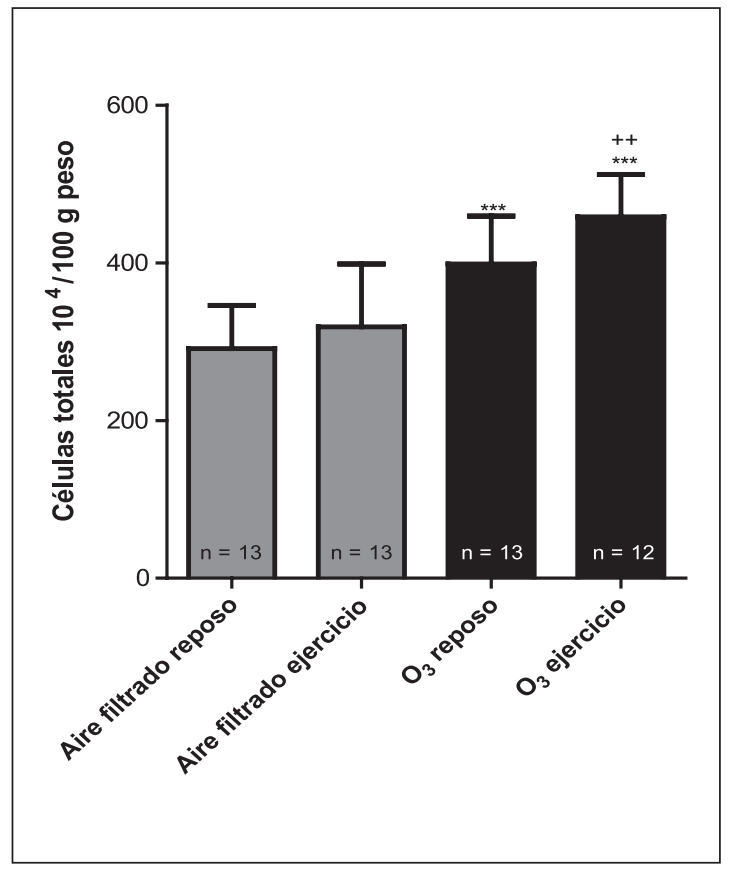

Figura 5. Células totales del lavado broncoalveolar (LBA) en ratas expuestas a 0,5 ppm de $\mathrm{O}_{3}$ o a aire filtrado en reposo y en ejercicio. $++\mathrm{p}<0,0001$ al comparar series con ozono en reposo versus ozono en ejercicio. $* * * p<0,05$ al comparar series con ozono versus series en aire filtrado.

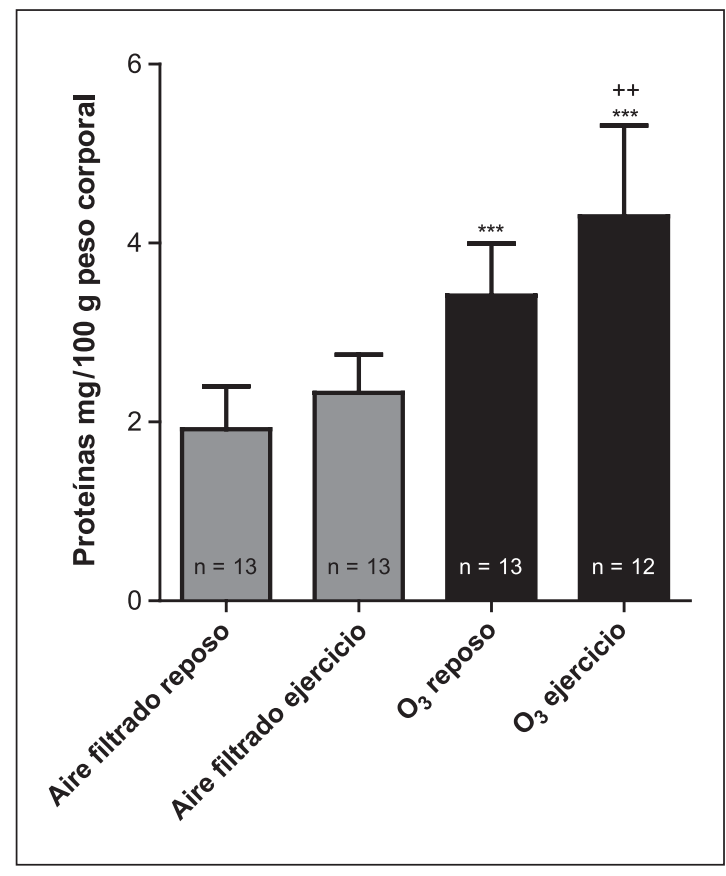

Figura 6. Proteínas totales (mg/100 g de peso corporal) del LBA en ratas expuestas a $0,5 \mathrm{ppm}$ de $\mathrm{O}_{3} \mathrm{o}$ a aire filtrado en reposo y en ejercicio. $++\mathrm{p}<0,0001$ al comparar series con ozono en reposo versus ozono en ejercicio. $* * * \mathrm{p}<0,05$ al comparar series con ozono versus series con aire filtrado. 


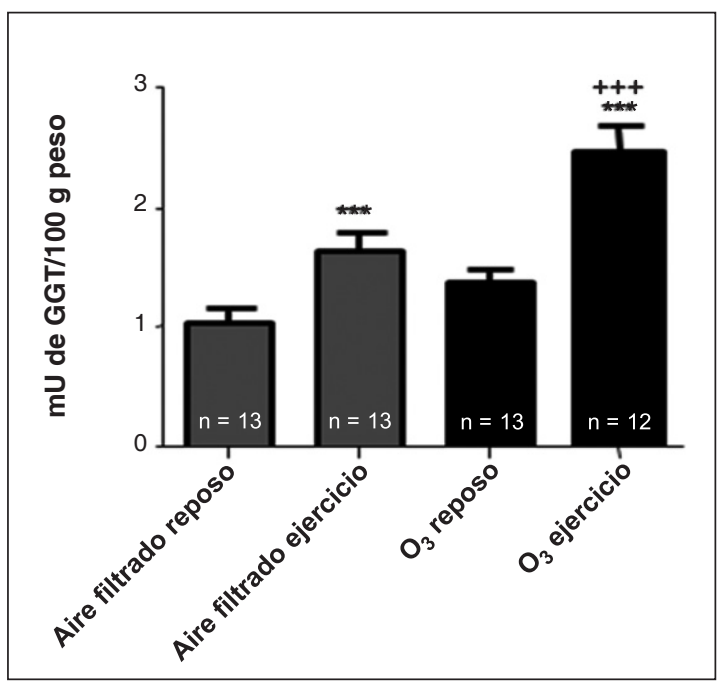

Figura 7. Actividad de $\gamma$-glutamil transpeptidasa: GGT (mU/100 g de peso corporal) en el LBA de ratas expuestas a $0,5 \mathrm{ppm}$ de $\mathrm{O}_{3}$ o a aire filtrado en reposo y en ejercicio. $+++\mathrm{p}<0,0001$ al comparar series en ejercicio con aire filtrado versus ozono. $* * * p<0,05$ al comparar series en reposo versus series con ejercicio.

\section{Discusión}

Los resultados obtenidos indican que el ejercicio físico aumenta el daño pulmonar inducido por la exposición aguda e intermitente a ozono 0,5 ppm durante $4 \mathrm{~h}$ diarias por dos días seguidos en ratas Sprague-Dawley juveniles. En este sentido, en la relación peso pulmonar/peso corporal (PP/PC) y la relación peso húmedo/peso seco del pulmón (PH/PS), existe una diferencia significativa $(p<0,05)$ entre las serie control y las series expuestas a ozono. La razón PH/PS indica un aumento del contenido acuoso del pulmón en las ratas expuestas a $\mathrm{O}_{3}$. Este aumento se explicaría por edema pulmonar e inflamación. El ozono promueve la liberación de factores proinflamatorios, como leucotrieno $\mathrm{B}_{4}$ y prostaglandina $\mathrm{F}_{2 \alpha}$, desde las células del epitelio respiratorio y desde los polimorfonucleares que aumentan en la inflamación neutrofílica que provoca la inhalación de este contaminante, induciendo un aumento de la permeabilidad vascular, lo que favorece el paso de líquido plasmático al intersticio pulmonar y eventualmente a los espacios aéreos ${ }^{15}$. Los macrófagos acumulados en el epitelio pulmonar, cuya migración es inducida por los factores proinflamatorios de neumocitos $\mathrm{I}^{16}$, amplifican la respuesta inflamatoria producto del estrés oxidativo inducido por la exposición a ozono ${ }^{17,18}$ y esto se acompaña de un aumento del flujo sanguíneo pulmonar, lo cual contribuiría a explicar el aumento de la razón PP/PC y especialmente de la razón $\mathrm{PH} / \mathrm{PS}$.

El aumento significativo de las células totales, se podría explicar por tres situaciones distintas, que podrían estar ocurriendo paralelamente en diversos grados de intensidad. La primera es el paso de macrófagos y polimorfonucleares, inducido por los factores proinflamatorios epiteliales, hacia el lumen alveolar, en presencia de ozono ${ }^{19}$. La segunda situación correspondería al paso indiferenciado de células sanguíneas del sistema inmune, por un aumento de la perfusión sanguínea producto de los factores proinflamatorios, amplificados por acción de los macrófagos en presencia de ozono ${ }^{20}$. La tercera situación que explicaría la presencia de células en el LBA es la descamación del epitelio de las vías aéreas inducido por el estrés oxidativo que provoca el ozono ${ }^{21}$.

El aumento de las proteínas totales en el LBA podría ser explicado por el aumento de la permeabilidad alvéolo-capilar, lo cual induce el paso de proteínas plasmáticas al lumen alveolar ${ }^{21}$. Otro factor que sumado al aumento de la permeabilidad capilar podría contribuir al aumento de proteínas, es el aumento focalizado del flujo sanguíneo pulmonar inducido por factores proinflamatorios liberados por neumocitos I y potenciados por macrófagos en presencia de ozono $^{18}$. Además hay que considerar que la exposición prolongada (por 3 a 7 días) a $0,4 \mathrm{ppm}$ de $\mathrm{O}_{3}$ aumenta la expresión de hemo-oxigenasa 1 en el pulmón de rata ${ }^{22}$, lo que es considerado un mecanismo protector por su papel antioxidante. Sin embargo, la hemo-oxigenasa-1 es también capaz de incrementar la producción de monóxido de carbono endógeno, que ha sido reconocido como vasodilatador de la circulación pulmonar ${ }^{23}$, lo que podría implicar otro mecanismo de aumento del flujo pulmonar post-exposición a ozono. Otro factor contribuyente al aumento de proteínas en el LBA podría ser el daño de las células epiteliales y endoteliales y de la membrana basal observado en la microscopía electrónica del pulmón de ratones expuestos $\mathrm{a} \mathrm{O}_{3}{ }^{24}$.

La $\gamma$-glutamiltranspeptidasa es una enzima que se encuentra en la membrana de los neumocitos II y en las células de Clara, por lo que un aumento de esta enzima en el LBA podría indicar daño celular específico de estas células. Cabe mencionar que se ha observado un aumento del mRNA de GGT en el pulmón de rata luego de exposiciones a 0,4 ppm de $\mathrm{O}_{3}$ durante 3 y 7 días alcanzando concentraciones cercanas al $150 \%$ del valor control, por lo que se ha planteado que la expresión de GGT podría tener participación en el proceso de recuperación del pulmón, luego de la expo- 
sición a $\mathrm{O}_{3}$, aunque no estaría involucrada en la respuesta respiratoria aguda a este contaminante ya que no hubo aumento de GGT luego de un día de exposición ${ }^{22}$.

El aumento de la actividad de GGT en las ratas que realizaron ejercicio respecto a las que se mantuvieron en reposo en los grupos expuestos a ozono, se explicaría porque el ejercicio aumenta la dosis efectiva de $\mathrm{O}_{3}$, lo que implica un mayor daño a nivel respiratorio. Por otra parte el aumento de la GGT en las ratas que realizaron ejercicio respirando aire filtrado respecto a las que estaban en reposo con aire filtrado, se podría explicar porque el ejercicio que realizaron estas ratas fue especialmente estresante para estos animales habituados a una vida sedentaria, ya que desde su nacimiento estuvieron confinados a su hábitat del bioterio, lo cual desde ya limita su capacidad de ejercicio respecto a una rata silvestre, lo que además pudo haber provocado un daño alvéolocapilar por aumento excesivo del flujo sanguíneo pulmonar en un animal con escasa adaptación al ejercicio aeróbico. Otro factor a considerar es que estos roedores habitualmente realizan ejercicio (carreras de corta duración) en base a su metabolismo anaeróbico. En nuestro diseño experimental estuvieron sometidas a carreras intermitentes de $15 \mathrm{~min}$ a una velocidad de $2,75 \mathrm{~m} /$ min lo que pudo haber provocado en ellas estrés oxidativo y liberación de especies reactivas del $\mathrm{O}_{2}$ que podrían dar cuenta del daño pulmonar detectado en estas series y que fue incrementado por la exposición a ozono. En atletas de elite que practican karate se ha encontrado aumento de GGT y proteínas en la orina, lo cual sería concordante con nuestros resultados en LBA de ratas post-ejercicio ${ }^{25}$.

El ejercicio no sólo aumenta la ventilación minuto, la cual eleva la dosis efectiva de $\mathrm{O}_{3}$, lo cual significa que a una misma concentración de $\mathrm{O}_{3}$ la dosis efectiva es mayor que en reposo, sino que representa un estado de mayor demanda metabólica, lo cual significa un aumento del consumo de $\mathrm{O}_{2}$, principalmente muscular y para satisfacerlo el organismo debe aumentar el gasto cardiaco y la diferencia arterio-venosa de $\mathrm{O}_{2}$. Esta situación aumenta el flujo sanguíneo sistémico y pulmonar, provocando un estrés mecánico en los vasos sanguíneos, como ha sido demostrado recientemente en hombres y mujeres después de un ejercicio extenuante ${ }^{26}$. Si este estrés vascular post-ejercicio afectase también a la circulación pulmonar, podría acoplarse a una mayor tracción de las estructuras pulmonares, favoreciendo algún grado de daño mecánico de la barrera alvéolo capilar $^{27}$, que sumado al estrés oxidativo producido por el $\mathrm{O}_{3}$ y el ejercicio explicaría los resultados obtenidos.

Considerando las diferencias fisiológicas, metabólicas y toxicológicas que puede tener la rata comparada con el ser humano, debemos ser prudentes al intentar extrapolar los resultados obtenidos en animales de experimentación al ser humano. Sin embargo, se ha comunicado que la exposición a $\mathrm{O}_{3}(0,25$ ppm por $2 \mathrm{~h}$ durante 4 días $)$ en voluntarios aumenta sus efectos nocivos en el pulmón con la realización de ejercicio físico ${ }^{28}$, por lo tanto, los datos obtenidos en este estudio, aunque obtenidos con una concentración más alta de $\mathrm{O}_{3}$, son concordantes con las observaciones realizadas en voluntarios expuestos a $\mathrm{O}_{3}$ durante ejercicio físico.

En resumen, a la luz de los resultados encontrados en la interacción ozono-ejercicio en este estudio experimental y los obtenidos en voluntarios humanos con concentraciones aún más bajas de $\mathrm{O}_{3}{ }^{28,29}$, se puede concluir que los efectos deletéreos del ozono aumentan en condiciones de ejercicio físico y por lo tanto, es recomendable que las personas no realicen ejercicio durante períodos y en zonas en que la contaminación fotoquímica está elevada. Para alertar a la población de este riesgo es perentorio incrementar la red de monitores, especialmente en zonas recreacionales y de educación física en que se estime que el ozono y otros contaminantes aéreos puedan estar aumentados.

\section{Agradecimientos}

Al Dr. Sergio González B., director del Departamento de Anatomía Patológica, Pontificia Universidad Católica de Chile, por el estudio histopatológico de la serie preliminar con $1 \mathrm{ppm}$ de ozono y ejercicio. A los funcionarios del Programa de Fisiopatología, Srs. Jorge Guzmán O. y José Venegas B., por su valiosa asistencia técnica.

\section{Bibliografía}

1.- OYARZÚN M. Efectos del ozono troposférico en el sistema respiratorio. En: Cabrera S, Lissi G y Honeymann J eds: Radiación ultravioleta y salud. Editorial Universitaria 2005; págs. 283-95.

2.- CIENCEWICKI J, TRIVEDI S, KLEEBERGER S R. Oxidants and the pathogenesis of lung diseases. J Allergy Clin Immunol 2008; 122: 456-68.

3.- KAMPA M, CASTANAS E. Human health effects of air pollution. Environ Pollut 2008; 151: 362-7.

4.- BYOUNG-JU KIM, SOO-JONG HONG. Ambient air pollution and allergic diseases in children. Korean $\mathrm{J}$ Pediatr 2012; 55: 185-92. 
5.- FRANK R, LIU M C, SPANHAKE E W, MLYNAREK S, MACRI K, WEINMANN O G. Repetitive ozone exposure of young adults: Evidence of persistent small airway dysfunction. Am J Respir Crit Care Med 2001; 164: 1253-60.

6.- JÖRRES R A, HOLZ O, ZACHGO W, TIMM P, KOSCHYK S, MÜLLER B, et al. The effect of repeated ozone exposures on inflammatory markers in bronchoalveolar lavage fluid and mucosal biopsies. Am J Respir Crit Care Med 2000; 161: 1855-61.

7.- TAGER I B, BALMES J, LURMANN F, NGO L, ALCORN S, KÜNZLI N. Chronic exposure to ambient ozone and lung function in young adults. Epidemiology 2005; 16: 751-9.

8.- CHANG L Y, HUANG Y, STOCKSTILL B L, GRAHAM J A, GROSE E C, MENACHE M G, et al. Epithelial injury and interstitial fibrosis in the proximal alveolar regions of rats chronically exposed to a simulated pattern of urban ambient ozone. Toxicol Appl Pharmacol 1992; 115: 241-52.

9.- TYLER W S, TYLER N K, LAST J A, GILLESPIE M J, BARSTOW T J. Comparison of daily and seasonal exposures of young monkeys to ozone. Toxicology 1988; 50: 131-44.

10.- PEHNEC G, JAZBEC A, VAĐIĆ V, PAVLOVIĆ M. Effect of summer ozone concentrations on the lung function of walkers in the Medvednica Mountain Nature Park, Croatia. Arch Environ Occup Health 2011; 66: 223-30.

11.- EL HELOU N, TAFFLE MT, BERTHELOT G, TOLAINI J, MARC A, GUILLAUME M, et al. Impact of environmental parameters on marathon running performance PLoS One 2012; 7: e37407.

12.- GONG H Jr, BRADLEY P W, SIMMONS M S, TASHKIN D P. Impaired exercise performance and pulmonary function in elite cyclists during low-level ozone exposure in a hot environment. Am Rev Respir Dis 1986; 134 : 726-33.

13.- LOWRY O H, ROSEBROUGH N J, FARR A L, RANDALL R J. Protein measurement with the folin phenol reagent. J Biol Chem1951; 193: 265-75.

14.- VILLANUEVA S, PUENTE J, SAPAG-HAGAR M. Reaction of hormones on the rat uterus and mammary glands Gamma-Glutamyltranspeptidase. Res Comm Chem Pathol Phramacol 1987; 57: 99-105.

15.- LEIKAUF G D, ZHAO Q, ZHOU S, SANTROCK J. Ozonolysis products of membrane fatty acids activate eicosanoid metabolism in human airway epithelial cells. Am J Respir Cell Mol Biol 1993; 9: 594-602.

16.- SUNIL V R, PATEL-VAYAS K, SHEN J, LASKIN J D, LASKIN D L. Classical and alternative macrophage activation in the lung following ozone-induced oxidative stress. Toxicol Appl Pharmacol 2012; 263: 195-202.

17.- LASKIN D L, PENDINO K J. Macrophages and inflammatory mediators in tissue injury. Ann Rev Pharmacol Toxicol 1995; 35: 655-77.

18.- GARDI C, VALACCHI G. Cigarette smoke and ozone effect on murine inflammatory responses. Ann N Y Acad Sci 2012; 1259: 104-11.
19.- KOYAMA S, RENNARD S I, LEIKAUF G D, SHOJI S, VON ESSEN S, CLAASEN K, et al. Endotoxin stimulates bronchial epithelial cells to release chemotactic factors for neutrophils. J Immunol 1991; 147: 4293-301.

20.- COFFEY M J, WHEELER C S, GROSS K B, ESCHENBACHER W L, SPORN P H, PETERS-GOLDEN M. Increased 5-lipoxygenase metabolism in the lungs of human subjects exposed to ozone. Toxicology 1996; 114: 187-97.

21.- BARRY B E, MILLER F J, CRAPO J D. Alveolar epithelial injury caused by inhalation of 0.25 ppm ozone. En: Lee. S.D., Mustafa, M.G., Mehlman, M.A. (eds.) "International Symposium on the biomedical effects of ozone and related photochemical oxidants." Princeton Scientific Publishers 1983; 5: 299-309.

22.- TAKAHASHI Y, TAKAHASHI S, YOSHIMI T, MIURA T, MOCHITATE K, KOBAYASHI T. Increases in the mRNA levels of gamma-glutamyltransferase and heme oxygenase-1 in the rat lung after ozone exposure. Biochem Pharmacol 1997; 4: 53: 1061-4.

23.- NACHAR R A, PASTENE C M, HERRERA E A, RIQUELME R A, SANHUEZA E M, TRONCOSO S, et al. Low-dose inhaled carbon monoxide reduces pulmonary vascular resistance during acute hypoxemia in adult sheep. High Altitude Med \& Biol 2001; 2: 377-85.

24.- INOUE K, TAKANO H, KAEWAMATAWONG T, SHIMADA A, SUZUKI J, YANAGISAWA R, et al. Role of metallothionein in lung inflammation induced by ozone exposure in mice. Free Radic Biol Med 2008; 45: 1714-22.

25.- SHAVANDI N, SAMIEI A, AFSHAR R, SAREMI A, SHEIKHHOSEINI R. The effect of exercise on urinary gamma-glutamyltransferase and protein levels in elite female karate athletes. Asian J Sports Med 2012; 3: 416.

26.- DOONAN R J, MUTTER A, EGIZIANO G, GÓMEZ Y H, DASKALOPOULOU S S. Differences in arterial stiffness at rest and after acute exercise between young men and women. Hypertens Res 2012 Oct 11. doi:10.1038/hr.2012.158. [Epub ahead of print].

27.- CHIMENTI L, MORICI G, PATERNÒ A, SANTAGATA R, BONANNO A, PROFITA M, et al. Bronchial epithelial damage after a half-marathon in nonasthmatic amateur runners. Am J Physiol Lung Cell Mol Physiol 2010; 298: 857-62.

28.- FRAMPTON M W. Ozone air pollution: how low can you go? Am J Respir Crit Care Med 2011; 184: 150-1.

Correspondencia a:

Dr. Manuel Oyarzún G.

Avda. Salvador 486, Providencia, Santiago.

Email: moyarzun@med.uchile.cl 